\title{
Safety and Efficacy of Ultra-Thin, Biodegradable Polymer Coated Sirolimus-Eluting Supralimus-Core Stents in Real-World Patients: Outcomes at 24-Month Follow-Up
}

\author{
Kala Jeethender Kumar Jain*, Subash Dasarapu, Sai Satish Oruganti, Jyotsna Maddury, \\ Srinivas Bhyravavajhala, Rama Kumari Nuthalapati, Vanaparthi Satya Bharathi Lakshmi, \\ Rajender Betham, Anil Kumar Enikapalli
}

Nizam's Institute of Medical Sciences, Hyderabad, Telangana, India

Email: *jeetu_jain24@yahoo.com

How to cite this paper: Jain, K.J.K., Dasarapu, S., Oruganti, S.S., Maddury, J., Bhyravavajhala, S., Nuthalapati, R.K., Lakshmi, K.S.B., Betham, R. and Enikapalli, A.K. (2018) Safety and Efficacy of Ultra-Thin, Biodegradable Polymer Coated Sirolimus-Eluting Supralimus-Core Stents in Real-World Patients: Outcomes at 24-Month Follow-Up. World Journal of Cardiovascular Diseases, $\mathbf{8}$, 523-532.

https://doi.org/10.4236/wjcd.2018.811051

Received: November 2, 2018

Accepted: November 27, 2018

Published: November 30, 2018

Copyright (c) 2018 by authors and Scientific Research Publishing Inc. This work is licensed under the Creative Commons Attribution International License (CC BY 4.0).

http://creativecommons.org/licenses/by/4.0/

\section{(c) (i) Open Access}

\begin{abstract}
Aim: The purpose of this registry was to establish long-term safety and efficacy through implantation of Supralimus-Core sirolimus-eluting stents (SES) in real-world patients with coronary artery disease (CAD). Methods: The present registry was a retrospective, singe-arm, single-centre, investigator-initiated registry. A total of 372 consecutive patients were implanted with Supralimus-Core SES between January 2015 and November 2016. The primary endpoints were major adverse cardiac events (MACE), a composite of cardiac death, myocardial infarction (MI), target lesion revascularization (TLR) and target vessel revascularization (TVR) at 24 months. The secondary endpoints were all-cause death and all separate components of the primary endpoint. Additional endpoints included events of stent thrombosis classified as definite, probable, and possible stent thrombosis. Follow-ups were conducted at 30-days, 6-months, 12 -months and 24-months after the index procedure. Results: The mean age of the registry population was $56.3 \pm 11.1$ years. Males constituted 276 (74.2\%) patients. Hypertensives, diabetics, alcoholics, tobacco chewers and smokers comprised 198 (53.2\%), 160 (43.0\%), 93 (25.0\%), 91 (24.5\%) and 88 (23.7\%) of the registry population, respectively. The mean length and diameter of stents implanted was $19.3 \pm 8.8 \mathrm{~mm}$ and 2.9 $\pm 0.3 \mathrm{~mm}$, respectively. At the 24-month follow-up, MACE was reported in $14(3.8 \%)$ patients. Cardiac death, MI, TLR and TVR was reported in 7 $(1.9 \%), 4(1.1 \%), 3(0.8 \%)$ and $4(1.1 \%)$ patients, respectively. Overall stent thrombosis occurred in $4(1.1 \%)$ patients. Conclusions: The low MACE rate of $3.8 \%$ at the 24 -month follow-up indicates favorable long-term results after implantation of the ultra-thin strut Supralimus-Core SES in all-comer,
\end{abstract}


real-world patients.

\section{Keywords}

Biodegradable Polymer, Cobalt-Chromium, Coronary Artery Disease, Drug Eluting Stents, Percutaneous Coronary Intervention, Sirolimus-Eluting Stent

\section{Introduction}

Percutaneous coronary intervention (PCI) has emerged as the standard treatment for coronary artery disease (CAD) [1]. Naturally, stent design has rapidly evolved over the past decades. Bare-metal stents (BMS) were the first stents licensed for use in cardiac arteries [2]. These BMS caused neointimal hyperplasia consequential of proliferation and migration of smooth muscle cells and extracellular matrix production [3]. The resultant restenosis rates led to the downfall of BMS and inception of the drug-eluting stent (DES) era. The first generation DES incorporated release of an antiproliferative drug from a permanent polymer coated on a BMS platform. The drug sirolimus displayed efficacy in preventing hyperplasia due to vascular injury after stent implantation. Hence, it is being considered as an agent for prevention of restenosis [4]. Although these stents achieved reduced restenosis and revascularization rates, presence of the permanent polymer is linked to delayed healing, inflammatory reactions, hypersensitive reactions, and late and very late thrombosis [3]. To resolve this issue, second generation stents were introduced. These stents have the advantage of a biodegradable polymer. The polymer degrades after drug elution to avoid unfavourable effects due to their permanent existence [3]. Polymer degradation reduces local inflammatory reaction and irritation, leaving behind only a metal stent adhered to the artery wall [2]. Despite this benefit, concerns regarding long-term safety and efficacy are still prevalent.

Supralimus-Core sirolimus-eluting stent (SES) (Sahajanand Medical Technologies Pvt. Ltd., Surat, India) utilizes a $60 \mu \mathrm{m}$ ultra-thin, L605 cobalt-chromium stent platform coated with a biodegradable polymer for delivery of sirolimus drug. This ultra-thin platform provides flexibility for easy deliverability [3]. The serpentine strut design permits uniform stress distribution at expansion whereas alternate links permit vessel trackability [2]. The present registry aimed to establish long-term safety and efficacy through implantation with Supralimus-Core SES in a "real-world" population.

\section{Materials and Methods}

\section{Study design and patient population}

This was a retrospective, singe-arm, single-centre, investigator-initiated registry conducted at a tertiary-care centre in India. Patients, diagnosed with CAD and underwent PCI with at least one Supralimus-Core SES between January 
2015 and August 2016, were included in the registry. The registry was aimed at studying a "real-world" population; hence, no major clinical or angiographic exclusion criteria were defined. All patients provided informed consent for the procedure, and subsequent data collection and analysis for the research purpose.

\section{Description of study stent}

The Supralimus-Core SES has a $60 \mu \mathrm{m}$ thin stent platform made of L605 cobalt-chromium alloy. This platform is coated with a combination of biodegradable polymers and $1.4 \mu \mathrm{g} / \mathrm{mm}^{2}$ sirolimus drug. This coating is conformal around the stent struts and is not limited to the abluminal surface of the stent. The biodegradable polymer matrix comprises poly L-lactide (PLLA), 50/50 poly DL-lactide-co-glycolide (PLGA) and polyvinyl pyrrolidone (PVP), which control drug release from the stent. Approximately $70 \%$ of the drug is released within 7 days whilst the remaining drug is released over an interval of 48 days [4]. After drug release, the polymers degrade naturally and are excreted from the body in the form of their metabolites. The average coating thickness of Supralimus-Core ranges from 5 - $6 \mu \mathrm{m}$. Supralimus-Core was made available in lengths of 8,12 , $16,20,24,28,32,36$ and $40 \mathrm{~mm}$ and diameters of $2.5,2.75,3.0$ and $3.5 \mathrm{~mm}$ during the registry.

\section{Interventional procedure and adjunctive medications}

All procedures and medication regimes followed standard hospital procedures. Other devices were also permitted however, stent implantation with a Supralimus-Core SES was mandatory. Pre-procedure patients were administered a dose of $300 \mathrm{mg}$ clopidogrel orally 24 hours before the procedure. An intra-arterial bolus of $100 \mathrm{IU} / \mathrm{kg}$ unfractionated heparin was administered to patients to achieve an activated clotting time $\geq 250 \mathrm{sec}$ and to initiate the procedure. Administration of glycoprotein IIb/IIIa inhibitors IIb/IIIa inhibitor was left to the investigator's discretion. Post-procedural antiplatelet regimen included indefinite aspirin therapy (75 mg/day) along with clopidogrel orally for at least 6 after the procedure.

\section{Data collection and patient follow-up}

Demographic data such as age, gender, cardiovascular risk factors and cardiovascular history were extracted from patient hospital records. Details of affected lesions and stent implantation were collected from angiography and angioplasty reports. Adverse events, angina status, and cardiovascular medication intake were assessed during hospital stay. Patients were followed up at 30-day, 6-months, 12-months and 24-months. The follow-up data were collected retrospectively from existing databases where index and follow-up data existed or was obtained by telephonic contact.

\section{Study endpoints}

The primary endpoint of the registry was major adverse cardiac event (MACE). MACE was defined as a composite of cardiac death, myocardial infarction (MI), target lesion revascularization (TLR) and non-target lesion target vessel revascularization (non-TL TVR). The secondary endpoints included all-cause death and all separate components of the primary endpoint. Additional end- 
points included events of stent thrombosis classified as definite, probable, and possible stent thrombosis based on the criteria defined by the Academic Research Consortium (ARC) [5].

Death due to undetermined cause was defined as cardiac death unless a non-cardiac cause was established through clinical and/or pathological study. MI was defined as either development of new pathological Q waves in at least two contiguous leads of the electrocardiogram with or without elevated cardiac enzymes or elevation of creatine kinase greater than three times the upper limit of normal and without pathological Q waves in the electrocardiogram. TLR was considered when there was stenosis in the treated segment $(5 \mathrm{~mm}$ proximal and $5 \mathrm{~mm}$ distal edges). TVR was defined as repeat revascularization of the same vessel treated in the index procedure. Stent thrombosis was defined as: "definite" when detected angiographically; "probable" if the patient had a target vessel-related MI or died of a coronary event within the first 30 days; and "possible" if any unexplained death occurred from 30 days after the index procedure until the final follow-up.

\section{Statistical analysis}

Continuous variables are represented as means with standard deviations and categorical variables as counts and percentages. All data were processed using the Statistical Package for Social Sciences (SPSS, Chicago, IL, USA) program version 15. The Kaplan-Meier graph was used to summarize cumulative MACE at 24 months.

\section{Results}

\section{Baseline demographic characteristics}

This registry comprised of 372 patients. The mean age of the registry population was $56.3 \pm 11.1$ years and males constituted 276 (74.2\%) patients. Hypertension, diabetes mellitus, alcoholism, tobacco chewing and smoking were the leading cardiovascular risk factors present in 198 (53.2\%), 160 (43.0\%), 93 (25.0\%), 91 (24.5\%) and 88 (23.7\%) patients, respectively. Previous PCI occurred in $30(8.1 \%)$ patients and stroke occurred in $5(1.3 \%)$ patients. The baseline demographic characteristics are presented in Table 1.

\section{Angiographic and procedural characteristics}

A total of 372 patients were implanted with 495 stents to treat 488 coronary lesions. The target lesion was most commonly located in the left anterior descending artery 231 (47.3\%), followed by the right coronary artery $162(33.2 \%)$ and the left circumflex artery 96 (19.5\%). Lesions were classified according to the American College of Cardiology/American Heart Association. There were 34 (7.0\%) type A lesions, 236 (48.4\%) type B1 lesions, 69 (14.1\%) type B2 lesions and 149 (30.5\%) type $C$ lesions. An average of $1.3 \pm 0.5$ stents was implanted per patient and $1.0 \pm 0.5$ stent implanted per lesion. The average stent length and diameter were $19.3 \pm 8.8 \mathrm{~mm}$ and $2.9 \pm 0.3 \mathrm{~mm}$ respectively. The angiographic procedural details are outlined in Table 2. 
Table 1. Baseline demographic characteristics.

\begin{tabular}{cc}
\hline Characteristics & $\begin{array}{c}\text { Supralimus-Core SES } \\
\mathrm{n}=\mathbf{3 7 2} \text { patients }\end{array}$ \\
\hline Age (mean \pm SD, years) & $56.3 \pm 11.1$ \\
Male, n (\%) & $276(74.2 \%)$ \\
Cardiovascular risk & \\
Hypertension, n (\%) & $198(53.2 \%)$ \\
Diabetes mellitus, n (\%) & $160(43.0 \%)$ \\
Alcoholism, n (\%) & $93(25.0 \%)$ \\
Tobacco chewer, n (\%) & $91(24.5 \%)$ \\
Smoker, n (\%) & $88(23.7 \%)$ \\
Hypercholesterolemia, n (\%) & $6(1.6 \%)$ \\
Family history of coronary artery disease, $\mathrm{n}(\%)$ & $9(2.4 \%)$ \\
Previous MI, n (\%) & $0(0 \%)$ \\
Previous CABG, n (\%) & $0(0 \%)$ \\
Previous PCI, n (\%) & $30(8.1 \%)$ \\
Previous stroke, n (\%) & $5(1.3 \%)$ \\
\hline
\end{tabular}

MI-myocardial infarction, CABG-coronary artery bypass graft, $\mathrm{PCI}-$ percutaneous coronary intervention.

Table 2. Angiographic and procedural characteristics.

\begin{tabular}{|c|c|}
\hline Characteristics & Patients $=372 /$ Lesions $=488$ \\
\hline No. of diseased vessels & $\mathrm{N}=372$ \\
\hline Single vessel disease, $\mathrm{n}(\%)$ & $258(69.4 \%)$ \\
\hline Double vessel disease, $\mathrm{n}(\%)$ & $111(29.8 \%)$ \\
\hline Triple vessel disease, $\mathrm{n}(\%)$ & $3(0.8 \%)$ \\
\hline Lesion location & $\mathrm{N}=488$ \\
\hline Left anterior descending, $\mathrm{n}(\%)$ & $231(47.3 \%)$ \\
\hline Right coronary artery, n (\%) & $162(33.2 \%)$ \\
\hline Left circumflex artery, $\mathrm{n}(\%)$ & $96(19.5 \%)$ \\
\hline ACC/AHA lesion classification & $\mathrm{N}=372$ \\
\hline $\mathrm{A}, \mathrm{n}(\%)$ & $34(7.0 \%)$ \\
\hline $\mathrm{B} 1, \mathrm{n}(\%)$ & $236(48.4 \%)$ \\
\hline $\mathrm{B} 2, \mathrm{n}(\%)$ & $69(14.1 \%)$ \\
\hline $\mathrm{C}, \mathrm{n}(\%)$ & $149(30.5 \%)$ \\
\hline Total no. of stent & $N=495$ \\
\hline No. of stents per patient, (mean $\pm \mathrm{SD}, \mathrm{mm})$ & $1.3 \pm 0.5$ \\
\hline No. of stents per lesion, (mean $\pm \mathrm{SD}, \mathrm{mm})$ & $1.0 \pm 0.5$ \\
\hline Stent length, (mean $\pm \mathrm{SD}, \mathrm{mm})$ & $19.3 \pm 8.8$ \\
\hline Stent diameter, (mean $\pm \mathrm{SD}, \mathrm{mm})$ & $2.9 \pm 0.3$ \\
\hline
\end{tabular}

ACC/AHA-American College of Cardiology/American Heart Association. 


\section{Clinical outcomes}

Follow-up was available for 365 (98.9\%) patients at up to 24-month follow-up. MACE occurred in 4 (1.1\%), 8 (2.2\%), $11(3.0 \%)$ and $14(3.8 \%)$ patients at 30-day, 6-month, 12-month and 24-month follow-ups, respectively. The clinical outcomes at 30-day, 6-month, 12-month and 24-month follow-ups are presented in Table 3. At 24-month follow-up, MACE comprised of 7 (1.9\%) cardiac death, $4(1.1 \%)$ MI, 3 (0.8\%) TLR and 4 (1.1\%) TVR, respectively. The Kaplan-Meier graph for cumulative MACE is shown in Figure 1. Overall stent thrombosis occurred in $2(0.5 \%), 3(0.8 \%), 3(0.8 \%)$ and $4(1.1 \%)$ patients at 30 -day, 6 -month, 12-month and 24-month follow-ups, respectively.

\section{Discussion}

The purpose of the current registry was to evaluate long-term safety and efficacy of the Supralimus-Core SES in real-world patients. The low MACE rates observed at $12(3.0 \%)$ and 24 months (3.8\%) demonstrate favorable results.

The ISAR-STEREO trial [6] compared strut thickness of coronary stents with stainless steel platforms. Angiographic and clinical restenosis reported were $15.0 \%$ vs. $25.8 \%$ and $8.6 \%$ vs. $13.8 \%$ in the thin and thick-strut stents, respectively. Similarly, the ISAR-STEREO 2 trial [7] reported angiographic restenosis and TVR due to restenosis $17.9 \%$ vs. $31.4 \%$ and $12.3 \%$ vs. $21.9 \%$ in the thin and thick-strut stents, respectively. These trials demonstrate that thin-strut stents elicit lower restenosis rates than thick-strut stents. In line with these findings, the $60 \mu \mathrm{m}$ thin Supralimus-Core demonstrated 3.3\% in-stent restenosis and $4.6 \%$ in-segment restenosis in the MAXIMUS study [3]. TVR was $1.1 \%$ at the 24-month follow-up in the present registry.

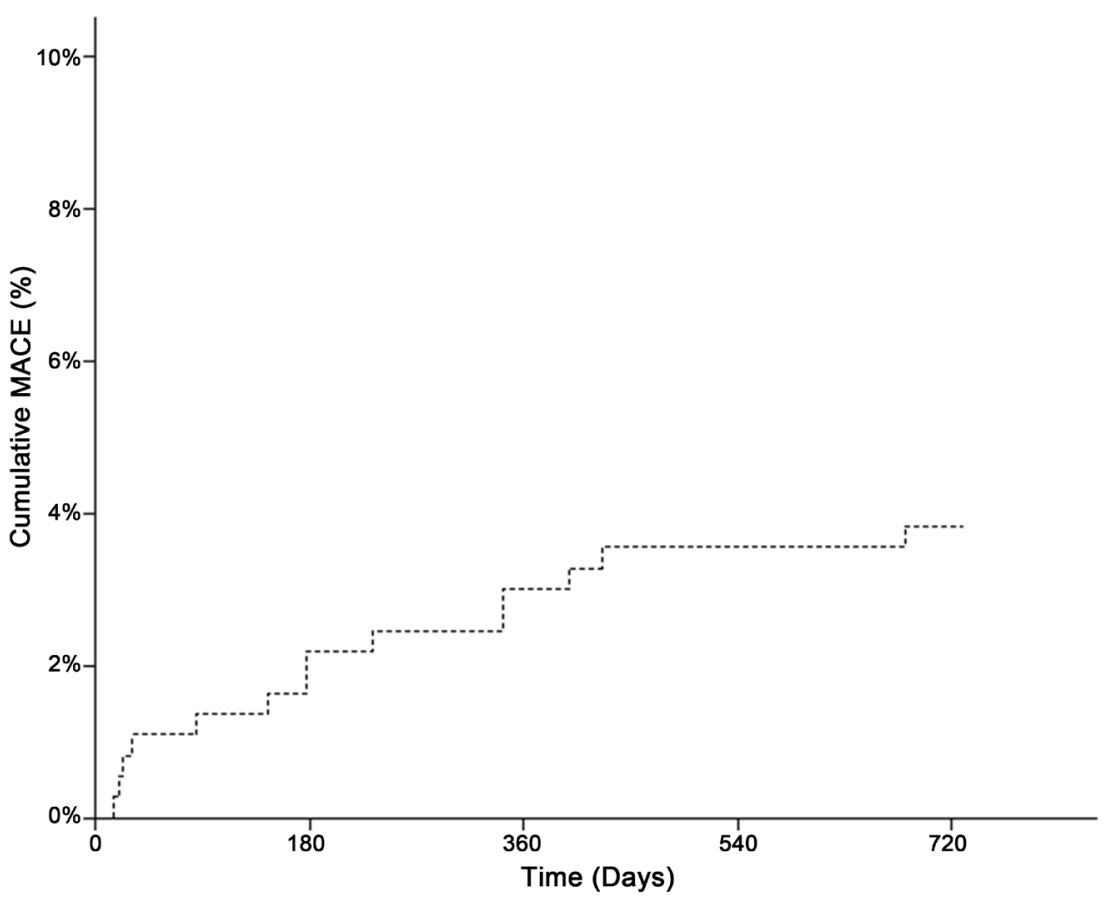

Figure 1. Kaplan-Meier graph for cumulative MACE. 
Table 3. Cumulative clinical outcomes at 30-day, 6-month, 12-month and 24-month follow-up.

\begin{tabular}{lcccc}
\hline \multicolumn{1}{c}{ Clinical outcomes } & $\begin{array}{c}\text { At 30 day } \\
\text { follow-up } \\
\text { N = 372 }\end{array}$ & $\begin{array}{c}\text { At 6 month } \\
\text { follow-up } \\
\mathbf{N}=372\end{array}$ & $\begin{array}{c}\text { At 12 month } \\
\text { follow-up } \\
\mathbf{N}=368\end{array}$ & $\begin{array}{c}\text { At 24 month } \\
\text { follow-up } \\
\text { N = 365 }\end{array}$ \\
\hline Death from any cause, n (\%) & $2(0.5 \%)$ & $6(1.6 \%)$ & $7(1.9 \%)$ & $10(2.7 \%)$ \\
Cardiac death, n (\%) & $2(0.5 \%)$ & $4(1.1 \%)$ & $5(1.4 \%)$ & $7(1.9 \%)$ \\
Non-cardiac death, n (\%) & $0(0 \%)$ & $2(0.5 \%)$ & $2(0.5 \%)$ & $3(0.8 \%)$ \\
Myocardial infarction, n (\%) & $2(0.5 \%)$ & $2(0.5 \%)$ & $3(0.8 \%)$ & $4(1.1 \%)$ \\
Target lesion revascularization, n (\%) & $0(0 \%)$ & $2(0.5 \%)$ & $3(0.8 \%)$ & $3(0.8 \%)$ \\
Target vessel revascularization, n (\%) & $0(0 \%)$ & $3(0.8 \%)$ & $4(1.1 \%)$ & $4(1.1 \%)$ \\
Overall stent thrombosis, n (\%) & $2(0.5 \%)$ & $3(0.8 \%)$ & $3(0.8 \%)$ & $4(1.1 \%)$ \\
Definite stent thrombosis, n (\%) & $1(0.3 \%)$ & $1(0.3 \%)$ & $1(0.3 \%)$ & $1(0.3 \%)$ \\
Probable stent thrombosis, $\mathrm{n}(\%)$ & $1(0.3 \%)$ & $2(0.5 \%)$ & $2(0.5 \%)$ & $3(0.8 \%)$ \\
Possible stent thrombosis, n (\%) & $0(0 \%)$ & $0(0 \%)$ & $0(0 \%)$ & $0(0 \%)$ \\
Major adverse cardiac events, $\mathrm{n}(\%)$ & $4(1.1 \%)$ & $8(2.2 \%)$ & $11(3.0 \%)$ & $14(3.8 \%)$ \\
\hline
\end{tabular}

Permanent polymers were the pitfall of first generation SES. These permanent polymers were associated with inflammation at the vessel site and delayed healing. These occurrences partially justify increased incidences of late stent thrombosis, very late stent thrombosis and long-term adverse effects [5]. This has in turn brought about the advent of biodegradable polymers. Degradation of the polymer reduces risks of stent thrombosis experienced with first generation stents as evidenced by several trials [8] [9] [10].

The Supralimus-Core fairs well when compared with other SES. The MeriT-2 [11], BIOFLOW-1 [12] and SORT OUT III [13] studies reported MACE in 15 $(6.0 \%), 3(10 \%)$ and $46(3.9 \%)$ patients at 12 months, respectively. The MAXIMUS study [3] reported 4.0\% MACE at 12 months whereas, the present registry reported $3.0 \%$ at 12 months. The low MACE rates observed in Supralimus-Core studies imply long-term safety and efficacy.

MACE rates are favourable with the Supralimus-Core SES even at the 24-month follow-up. The SPIRIT III [14] trial reported MACE in $49(7.7 \%)$ and $42(13.8 \%)$ patients in everolimus-eluting stent (EES) and paclitaxel-eluting stent (PES) groups, respectively [14]. Similarly, Erdim et al. [15] reported two-year MACE in 4 (8.3\%) and 13 (16.4\%) patients in SES and PES groups, respectively [15]. The SIRIUS trial [16] examined two-year clinical outcomes in patients with de novo native coronary lesions. The study reported MACE in 55 (10.3\%) and $132(25.1 \%)$ patients in SES and control stent groups, respectively [16]. The present registry reported MACE in $14(3.8 \%)$ patients at the 24-month follow-up. These previous studies indicate lower rates of MACE achieved with SES as compared to other control stents. These studies also highlight the even lower MACE rate Supralimus-Core has achieved compared to earlier studies of SES. 
This investigator-initiated registry, reports 30 -days, 6-month, 12 -month and 24-month clinical outcomes associated with implantation of Supralimus-Core SES in patients with coronary artery disease. The registry population comprised of 198 (53.2\%) hypertensives, 160 (43.0\%) diabetics, 93 (25.0\%) alcoholics, 91 (24.5\%) tobacco chewers and $88(23.7 \%)$ smokers. This population represents a high risk, real-world population. We believe the results of this registry could provide valuable insights regarding device performance and clinical outcomes in the routine clinical scenario.

\section{Study Limitations}

The major limitation of this registry is that it is a retrospective, investigator-initiated registry. The single-arm design of the registry limits the possibility of direct comparison with other DES.

\section{Conclusion}

The current registry evidences favorable long-term results after implantation of the ultra-thin strut Supralimus-Core SES in real-world patients.

\section{Conflicts of Interest}

The authors declare no conflicts of interest regarding the publication of this paper.

\section{References}

[1] Abhyankar, A.D. and Thakkar, A.S. (2012) In Vivo Assessment of Stent Recoil of Biodegradable Polymer-Coated Cobalt-Chromium Sirolimus-Eluting Coronary Stent System. Indian Heart Journal, 64, 541-546.

https://doi.org/10.1016/j.ihj.2012.07.005

[2] Banker, D., Ahuja, A., Sanadhya, H., Purohit, C., Chandra, S., Sethi, R., Khare, R., Kothari, S. and Thakkar, A. (2016) Clinical Performance of Biodegradable Polymer-Coated Sirolimus-Eluting Stents in Unselected Real-World Population with Coronary Artery Disease: Results from the Multicenter CORE Registry. Minerva Cardioangiologica, 64, 9-14.

[3] Seth, A., Chandra, P., Chouhan, N.S. and Thakkar, A.S. (2012) A First-in-Man Study of Sirolimus-Eluting, Biodegradable Polymer Coated Cobalt Chromium Stent in Real Life Patients. Indian Heart Journal, 64, 547-552. https://doi.org/10.1016/j.ihj.2012.07.011

[4] Thakkar, A.S., Abhyankar, A.D., Dani, S.I., Banker, D.N., Singh, P.I., Parmar, S.A, and Mehta, A.A. (2012) Systemic Exposure of Sirolimus after Coronary Stent Implantation in Patients with De Novo Coronary Lesions: Supralimus-Core ${ }^{\circledast}$ Pharmacokinetic Study. Indian Heart Journal, 64, 273-279. https://doi.org/10.1016/S0019-4832(12)60086-8

[5] Cutlip, D.E., Windecker, S., Mehran, R., Boam, A., Cohen, D.J., van Es, G.-A., Gabriel Steg, P., Morel, M.-A., Mauri, L. and Vranckx, P. (2007) Clinical End Points in Coronary Stent Trials: A Case for Standardized Definitions. Circulation, 115, 2344-2351. https://doi.org/10.1161/CIRCULATIONAHA.106.685313

[6] Kastrati, A., Mehilli, J., Dirschinger, J., Dotzer, F., Schuhlen, H., Neumann, F.-J., 
Fleckenstein, M., Pfafferott, C., Seyfarth, M. and Schömig, A. (2001) Intracoronary Stenting and Angiographic Results: Strut Thickness Effect on Restenosis Outcome (ISAR-STEREO) Trial. Circulation, 103, 2816-2821. https://doi.org/10.1161/01.CIR.103.23.2816

[7] Ürgen Pache, J., Kastrati, A., Mehilli, J., Schühlen, H., Dotzer, F., Örg Hausleiter, J., Fleckenstein, M., Neumann, F.-J., Sattelberger, U. and Schmitt, C. (2003) Intracoronary Stenting and Angiographic Results: Strut Thickness Effect on Restenosis Outcome (ISAR-STEREO-2) Trial. Journal of the American College of Cardiology, 41, 1283-1288. https://doi.org/10.1016/S0735-1097(03)00119-0

[8] Moses, J.W., Leon, M.B., Popma, J.J., Fitzgerald, P.J., Holmes, D.R., O’shaughnessy, C., Caputo, R.P., Kereiakes, D.J., Williams, D.O. and Teirstein, P.S. (2003) Sirolimus-Eluting Stents versus Standard Stents in Patients with Stenosis in a Native Coronary Artery. New England Journal of Medicine, 349, 1315-1323.

https://doi.org/10.1056/NEJMoa035071

[9] Serruys, P.W., Farooq, V., Kalesan, B., de Vries, T., Buszman, P., Linke, A., Ischinger, T., Klauss, V., Eberli, F. and Wijns, W. (2013) Improved Safety and Reduction in Stent Thrombosis Associated with Biodegradable Polymer-Based Biolimus-Eluting Stents versus Durable Polymer-Based Sirolimus-Eluting Stents in Patients with Coronary Artery Disease: Final 5-Year Report of the LEADERS (Limus Eluted from a Durable versus ERodable Stent Coating) Randomized, Noninferiority Trial. JACC: Cardiovascular Interventions, 6, 777-789. https://doi.org/10.1016/j.jcin.2013.04.011

[10] Han, Y., Jing, Q., Xu, B., Yang, L., Liu, H., Shang, X., Jiang, T., Li, Z., Zhang, H. and Li, H. (2009) Safety and Efficacy of Biodegradable Polymer-Coated Sirolimus-Eluting Stents in "Real-World" Practice: 18-Month Clinical and 9-Month Angiographic Outcomes. JACC Cardiovascular Interventions, 2, 303-309. https://doi.org/10.1016/j.jcin.2008.12.013

[11] Seth, A., Costa, R. and Kaul, U. (2016) Late Angiographic and Clinical Outcomes of the Novel BioMime ${ }^{\mathrm{Tm}}$ Sirolimus-Eluting Coronary Stent with Ultra-Thin Cobalt-Chromium Platform and Biodegradable Polymer for the Treatment of Diseased Coronary Vessels: Results from the Prospective, Multicentre meriT-2 Clinical Trial. Asialntervention, 2, 19-27.

[12] Hamon, M., Niculescu, R., Deleanu, D., Dorobantu, M., Weissman, N.J. and Waksman, R. (2013) Clinical and Angiographic Experience with a Third-Generation Drug-Eluting Orsiro Stent in the Treatment of Single De Novo Coronary Artery Lesions (BIOFLOW-I): A Prospective, First-in-Man Study. EuroIntervention, 8, 1006-1011. https://doi.org/10.4244/EIJV8I9A155

[13] Smits, P.C., Hofma, S., Togni, M., Vázquez, N., Valdés, M., Voudris, V., Slagboom, T., Goy, J.-J., Vuillomenet, A. and Serra, A. (2013) Abluminal Biodegradable Polymer Biolimus-Eluting Stent versus Durable Polymer Everolimus-Eluting Stent (COMPARE II): A Randomised, Controlled, Non-Inferiority Trial. Lancet, 381, 651-660. https://doi.org/10.1016/S0140-6736(12)61852-2

[14] Stone, G.W., Midei, M., Newman, W., Sanz, M., Hermiller, J.B., Williams, J., Farhat, N., Caputo, R., Xenopoulos, N. and Applegate, R. (2009) Randomized Comparison of Everolimus-Eluting and Paclitaxel-Eluting Stents: Two-Year Clinical Follow-Up from the Clinical Evaluation of the Xience V Everolimus Eluting Coronary Stent System in the Treatment of Patients with De Novo Native Coronary Artery Lesions (SPIRIT) III Trial. Circulation, 119, 680-686. https://doi.org/10.1161/CIRCULATIONAHA.108.803528

[15] Erdim, R., Helvacioglu, F., Gormez, S., Karabay, K.O. and Aytekin, V. (2012) Two-Year Follow-Up of Sirolimus-Eluting Stents versus Paclitaxel-Eluting Stents in 
Acute Myocardial Infarction. The International Journal of Angiology, 21, 53. https://doi.org/10.1055/s-0032-1302436

[16] Weisz, G., Leon, M.B., Holmes, D.R., Kereiakes, D.J., Clark, M.R., Cohen, B.M., Ellis, S.G., Coleman, P., Hill, C. and Shi, C. (2006) Two-Year Outcomes after Sirolimus-Eluting Stent Implantation: Results from the Sirolimus-Eluting Stent in de Novo Native Coronary Lesions (SIRIUS) Trial. Journal of the American College of Cardiology, 47, 1350-1355. https://doi.org/10.1016/j.jacc.2005.11.077 